\title{
Exercise training: can it improve cardiovascular health in patients with type 2 diabetes?
}

\section{K J Stewart}

Exercise training is an essential component of the management of patients with type 2 diabetes

M ost exercise training studies of patients with diabetes have focused on glycaemic control and less on the effects of exercise on cardiovascular health. Yet there are data from a variety of studies that provide strong, albeit not perfect, evidence that exercise training should be a standard of care not only for glycaemic control but for also improving the cardiovascular system in these patients.

\section{TYPE 2 DIABETES AND CARDIOVASCULAR HEALTH}

Type 2 diabetes is associated with dysfunction and failure of various organs, especially the heart and peripheral blood vessels. Both insulin resistance and $\beta$ cell dysfunction are contributing factors to the disease, ${ }^{12}$ as are environmental influences and genetic factors. ${ }^{3}$ It has also become clear that the increasing prevalence of obesity $^{1}$ and a sedentary lifestyle ${ }^{5}$ are also key contributors to the rising prevalence of type 2 diabetes in the United States and throughout the world. Two other metabolic conditions that precede the development of diabetes also have adverse effects on cardiovascular health and may also be prevented or delayed by regular exercise. Pre-diabetes is a metabolic condition that is between normal glucose homoeostasis and diabetes, ${ }^{6}$ and its prevalence in 2000 was estimated at nearly 12 million adults in the United States. ${ }^{7-9}$ The metabolic syndrome, which considerably increases the risk of developing diabetes, also stems from an underlying abnormality in insulin resistance..$^{10-13}$ Although type 2 diabetes increases the risk of microvascular complications such as retinopathy and nephropathy, ${ }^{14} 15$ most diabetic patients die from macrovascular complications including coronary artery disease and stroke, with an increased risk of these conditions of $200-400 \% .^{16}{ }^{17}$ Even before glucose concentrations reach the diagnostic threshold for diabetes, $25 \%$ of newly diagnosed patients may already have appreciable cardiovascular disease. $^{18}$

\section{EXERCISE TRAINING FOR MANAGING AND PREVENTING DIABETES}

The American College of Sports Medicine Position Stand on "Exercise and type 2 diabetes"19 says, "Physical activity, including appropriate endurance and resistance training, is a major therapeutic modality for type 2 diabetes." The American Diabetes Association Clinical Practice Recommendations $2001^{12}$ says "the possible benefits of exercise in type 2 diabetes are substantial." These guidelines are referring mainly to glycaemic control, whereas the recognition of the benefits of exercise training on cardiovascular health is now becoming more obvious. ${ }^{20}$ For example, in the National Health Interview Survey, ${ }^{21}$ among a diverse spectrum of adults with diabetes, walking was associated with a $39 \%$ lower all cause mortality and a 34\% lower cardiovascular disease mortality. It was estimated that one death a year could be prevented for every 61 people who would walk at least two hours a week, ${ }^{22}$ a goal that should be attainable by most people. Increased levels of exercise also play a role in preventing type 2 diabetes and related metabolic conditions. Men who engaged in three or more hours a week of moderate or vigorous leisure time physical activity reduced their risk of developing the metabolic syndrome by half over a four year follow up period. ${ }^{23}$ In the Health Professionals' Follow-up Study (HPFS), ${ }^{24}$ physical activity was associated with reduced risk of cardiovascular disease, cardiovascular death, and total mortality in men with type 2 diabetes after 14 years of follow up. In the multicultural insulin resistance atherosclerosis study, ${ }^{25}$ increased levels of moderate and intense physical activity were associated with higher insulin sensitivity. Among women in the Nurse's Health Study, ${ }^{26}$ sedentary behaviours, especially television watching, increased the risk of obesity and type 2 diabetes, whereas even light to moderate levels of activity reduced the risk of developing these conditions. In the Diabetes Prevention Program Research Group Study, ${ }^{27}$ which intervened on subjects at risk of diabetes, the lifestyle intervention reduced the risk of developing type 2 diabetes by $58 \%$ whereas pharmacological therapy reduced the incidence by $31 \%$. The lifestyle intervention included at least 30 minutes of moderate physical activity every day. Similar benefits of lifestyle intervention were also shown in older, obese Finnish men and women. ${ }^{28}$

There is also accumulating insight into the potential mechanisms by which cardiovascular health can be improved in these patients. Among the key mechanisms are improved endothelial vasodilator function, left ventricular diastolic function, arterial stiffness, and systematic inflammation. ${ }^{20}$ Furthermore, an often underappreciated benefit of exercise is that it also reduces total and abdominal visceral fat. Such changes in body composition with exercise training appear to mediate improvements in insulin sensitivity and blood pressure. ${ }^{20}$

\section{EXERCISE FOR PEOPLE WITH DIABETES}

Exercise guidelines for type 2 diabetes have been published by the American College of Sports Medicine, ${ }^{19}$ whereas guidelines from the American Diabetes Association can be found in their Handbook of exercise in diabetes. ${ }^{29}$ Because patients with diabetes often have concomitant clinical or occult coronary artery disease, adverse cardiovascular and physiological responses during exercise training are rare yet possible. The American Diabetes Association ${ }^{30}$ and Adult Treatment Panel (ATP) III guidelines ${ }^{31}$ consider diabetes as a coronary artery disease risk equivalent, and the prevalence of silent myocardial ischaemia in patients with type 2 diabetes can be as high as $20-25 \%$, especially in those over the age of $60,{ }^{32}$ or if there is the presence of other cardiovascular risk factors. ${ }^{33}$ Hence, these patients should undergo exercise stress testing before initiating a moderate intensity exercise programme or greater to identify ischaemia, arrhythmias, anginal thresholds, and patients with asymptomatic ischaemia. ${ }^{34-36}$ Exercise testing also evaluates the heart rate and blood pressure responses for establishing an appropriate exercise prescription.

Patients should accumulate a minimum expenditure of $1000 \mathrm{kcal}$ a week in 
aerobic exercise and participate in resistance training. ${ }^{37}{ }^{38}$ Most patients can meet this level by exercising three days a week, whereas more frequent sessions are recommended when weight loss is a goal. Each exercise session should include 5-10 minutes of warm up and 5-10 minutes of cool down activities. Appropriate activities for these phases are calisthenics, range of motion, and low intensity aerobic exercise, which allow gradual transition to and from the higher metabolic demands of the main aerobic phase of the exercise session. For aerobic exercise, walking, cycling, and swimming are well tolerated by most patients. These activities should gradually be increased in duration to last for 30-45 minutes to reach energy expenditure recommendations. ${ }^{36}$

Heart rate is the primary guide for aerobic exercise intensity. Whereas the target heart rate for exercise is typically set at $60-90 \%$ of the maximum heart rate for healthy adults, ${ }^{36}$ patients with diabetes, who are at risk of cardiovascular disease, should aim instead for a target heart rate corresponding to 55$79 \%$ of maximum. ${ }^{36}$ It is preferred that the maximal heart rate be obtained from exercise testing. ${ }^{34}$ In the absence of testing, and for patients whose heart rate response is not limited by drugs or autonomic neuropathy, ${ }^{35}$ the maximal heart rate can be estimated from age using the formula 220 minus age equals maximum heart rate (beats/min). In patients with a poor initial level of fitness, the target heart rate can be set at $50-60 \%$ of maximum and increased as tolerated. A lower heart rate range may also be necessary for patients with autonomic neuropathy, which limits the heart rate response during exercise. The use of $\beta$ blockers and abnormal exercise stress test findings will require individualised adjustment of the target heart rate. Although $\beta$ blockers attenuate the heart rate response to exercise, they will not generally preclude an improvement in aerobic and muscle fitness. ${ }^{39}$

The American College of Sports Medicine $^{19}$ and the American Heart Association in its "Scientific advisory on resistance training in individuals with and without cardiovascular disease $^{\prime \prime 40}$ recommend resistance training, when appropriately prescribed and supervised. The American Diabetes Association advises the use of light to moderate weights and high repetitions for maintaining or improving upper body strength for most patients with diabetes. ${ }^{41}$ For the elderly patient with diabetes, resistance training is especially important for its beneficial effects on bone density, osteoarthritic symptoms, mobility impairment, and self efficacy. ${ }^{42}$ It also alleviates symptoms of anxiety, depression, and insomnia in those with clinical depression. ${ }^{42}$ Resistance training should be performed at least twice a week, with a minimum of one set of 8-10 exercises to cover the large muscle groups of the upper and lower body..$^{43}$ If maximal muscle strength testing is available, 1 repetition maximum evaluation can be used to determine the patient's initial level of strength. ${ }^{44}$ The weight intensity for subsequent workouts is set at a moderate load of $30-50 \%$ of maximum strength. At this level, the patient should be able to perform 12-15 repetitions. When 15 repetitions of an exercise can be completed without difficulty, the weight can be increased by $5-10 \mathrm{lbs}$ to ensure a progressive overload. ${ }^{43}$ If muscle strength testing is not performed, the patient can, through trial and error, use an initial weight that can be lifted about 10-15 times. ${ }^{4045}$ Weight machines are recommended for their ease of use and safety, but hand weights, barbells, and elastic bands can also provide an adequate work out.

\section{EXERCISE PRECAUTIONS}

The risk-benefit of exercise is highly favourable for most patients with diabetes but some precautions are warranted. Moderate or severe hypertension (systolic blood pressure $\geqslant 160$ or diastolic blood pressure $\geqslant 100 \mathrm{~mm} \mathrm{Hg}$ ) should be controlled to lower levels before the start of an exercise programme. ${ }^{46}$ Although contraindications to exercise based on glycaemic control have been established for type 1 diabetes, ${ }^{29}$ guidelines for type 2 diabetes are only beginning to emerge. One study ${ }^{47}$ involving patients with type 2 diabetes with baseline glucose of $600-4000 \mathrm{mg} / \mathrm{l}$ found no episodes of ketosis or hypoglycaemia in the 24 hours after exercise, and the occurrence of hypoglycaemia (blood glucose $<600 \mathrm{mg} / \mathrm{l}$ ) during exercise was $2 \%$. Thus, patients with type 2 diabetes and not using insulin may not need their blood glucose routinely checked when exercising. Supplementary food should be available, but it is usually not required unless the exercise session is exceptionally vigorous and of long duration. ${ }^{19}$ Patients using insulin should be encouraged to exercise and be given instructions about blood glucose monitoring, insulin dosing, and supplementary foods. Precautions for patients with diabetic, peripheral, and autonomic neuropathy ${ }^{19} 29$ and peripheral arterial disease $\mathrm{e}^{48}$ are available elsewhere.

\section{CLINICAL IMPLICATIONS}

Exercise training is an essential component in the medical management of patients with type 2 diabetes. Besides the well established benefits for glycaemic control, the benefits of increasing physical activity on cardiovascular health are becoming more obvious. Persons who are in a pre-diabetic stage or have the metabolic syndrome may be able to prevent or delay the progression to overt diabetes by adopting a healthier lifestyle. Most people with or at risk of diabetes should be able to safely initiate an exercise programme after appropriate medical screening and development of an individualised exercise prescription. However, despite the increasing amount of evidence showing the benefits of exercise training, this modality of prevention and treatment continues to be underused. Although many patients lack the knowledge of the benefits of exercise or lose their motivation to participate, a lack of clear and specific guidelines from healthcare professionals is also an important factor contributing to its underuse. Clinicians should educate patients about the benefits of exercise for managing their type 2 diabetes and provide specific advice for increasing physical activity. It is insufficient to simply say "just walk some more." A formal referral to a qualified and experienced exercise professional is more likely to produce the results outlined herein. Many cardiac rehabilitation and clinical exercise programmes have considerable experience with patients with type 2 diabetes. Such programmes can establish individualised exercise prescriptions and provide an environment conducive to "lifestyle change" which underlies long term compliance to exercise and risk factor modification.

Br J Sports Med 2004;38:250-252. doi: $10.1136 / \mathrm{bjsm} .2004 .012187$

Correspondence to: Dr Stewart, Johns Hopkins Heart Health, Johns Hopkins Bayview Medical Center, 4940 Eastern Avenue, Baltimore, MD 21224, USA; kstewart@jhmi.edu, kerrystewar+@comcast.net

\section{REFERENCES}

1 Flegal KM, Carroll MD, Ogden CL, et al. Prevalence and trends in obesity among US adults, 1999-2000. JAMA 2002;288:1723-7.

2 Kahn CR. Banting Lecture. Insulin action diabetogenes, and the cause of type II diabetes. Diabetes 1994;43:1066-84.

3 Hsueh WC, Mitchell BD, Aburomia R, et al. Diabetes in the Old Order Amish: characterization and heritability analysis of the Amish Family Diabetes Study. Diabetes Care 2000;23:595-601

4 Kahn CR, Vicent D, Doria A. Genetics of noninsulin-dependent (type-II) diabetes mellitus. Annu Rev Med 1996;47:509-31.

5 Crespo CJ, Keteyian SJ, Heath GW, et al. Leisuretime physical activity among US adults. Results from the Third National Health and Nutrition Examination Survey. Arch Intern Med 1996;156:93-8.

6 Report of the expert committee on the diagnosis and classification of diabetes mellitus. Diabetes Care 2003;26(suppl 1):S5-20.

7 Benjamin SM, Valdez R, Geiss LS, et al. Estimated number of adults with prediabetes in the U.S. in 
2000: opportunities for prevention, Diabetes Care 2003;26:645-9.

8 de Vegt F, Dekker JM, Jager A, et al. Relation of impaired fasting and postload glucose with incident type 2 diabetes in a Dutch population: the Hoorn Study. JAMA 2001;285:2109-13.

9 Saydah SH, Loria CM, Eberhardt MS, et al. Subclinical states of glucose intolerance and risk of death in the U.S. Diabetes Care 2001;24:447-53.

10 Brotman DJ, Girod JP. The metabolic syndrome: a tug-of-war with no winner. Cleve Clin J Med 2002:69:990-4

11 Defronzo RA, Ferrannini E. Insulin resistance. A multifaceted syndrome responsible for NIDDM, obesity, hypertension, dyslipidemia, and atherosclerotic cardiovascular disease. Diabetes Care 1991;14:173-94.

12 American Diabetes Association. Clinical practice recommendations 2001. Diabetes Care 2001;24(suppl 1).

13 Narayan KM, Gregg EW, Fagot-Campagna A, et al. Relationship between quality of diabetes care and patient satisfaction. J Natl Med Assoc 2003:95:64-70.

14 Morgan CL, Currie CJ, Stott NC, et al. The prevalence of multiple diabetes-related complications. Diabet Med 2000;17:146-51.

15 Stratton IM, Adler Al, Neil HA, et al. Association of glycaemia with macrovascular and microvascular complications of type 2 diabetes (UKPDS 35): prospective observational study BMJ 2000;321:405-12.

16 Marks JB, Raskin P. Cardiovascular risk in diabetes: a brief review. J Diabetes Complications 2000; 14:108-15.

17 Blendea MC, S IM, Isenovic ER, Gick G, et al. Heart disease in diabetic patients. Curr Diab Rep 2003;3:223-9.

18 Wilson PW, Kannel WB. Obesity, diabetes, and risk of cardiovascular disease in the elderly. Am J Geriatr Cardiol 2002;11:119-23, 125.

19 Albright A, Franz M, Hornsby G, et al. American College of Sports Medicine position stand. Exercise and type 2 diabetes. Med Sci Sports Exerc 2000;32:1345-60.

20 Stewart KJ. Exercise training and the cardiovascular consequences of type 2 diabetes and hypertension: plausible mechanisms for improving cardiovascular health. JAMA 2002;288: 1622-31

21 Gregg EW, Gerzoff RB, Caspersen CJ, et al. Relationship of walking to mortality among US adults with diabetes. Arch Intern Med 2003; 163:1440-7.

22 Henriksen EJ. Invited review: effects of acute exercise and exercise training on insulin resistance. J Appl Physiol 2002;93:788-96.
23 Laaksonen DE, Lakka HM, Salonen JT, et al. Low levels of leisure-time physical activity and cardiorespiratory fitness predict development of the metabolic syndrome. Diabetes Care 2002;25:1612-18.

24 Tanasescu M, Leitzmann MF, Rimm EB, et al. Physical activity in relation to cardiovascular disease and total mortality among men with type 2 diabetes. Circulation 2003;107:2435-9.

25 Mayer-Davis EJ, D'Agostino R Jr, Karter AJ, et al. Intensity and amount of physical activity in relation to insulin sensitivity: the Insulin Resistance Atherosclerosis Study. JAMA 1998;279:669-74.

26 Hu FB, Li TY, Colditz GA, et al. Television watching and other sedentary behaviors in relation to risk of obesity and type 2 diabetes mellitus in women. JAMA 2003;289:1785-91.

27 Knowler WC, Barrett-Connor E, Fowler SE, et al. Reduction in the incidence of type 2 diabetes with lifestyle intervention or metformin. N Engl J Med 2002;346:393-403.

28 Tuomilehto J, Lindstrom J, Eriksson JG, et al. Prevention of type 2 diabetes mellitus by changes in lifestyle among subjects with impaired glucose tolerance. N Engl J Med 2001;344:1343-50.

29 Ruderman N, Devlin JT, Schneider S, et al. Handbook of exercise in diabetes. 2nd ed. Alexandria, VA: American Diabetes Association, 2002.

30 American Diabetes Association. Clinical practice recommendations 2002. Diabetes Care 2002;25(suppl 1):S1-147.

31 Third Report of the National Cholesterol Education Program (NCEP) Expert Panel on Detection, Evaluation, and Treatment of High Blood Cholesterol in Adults (Adult Treatment Panel III) final report. Circulation 2002; 106:3143-421.

32 Inoguchi T, Yamashita T, Umeda F, et al. High incidence of silent myocardial ischemia in elderly patients with non insulin-dependent diabetes mellitus. Diabetes Res Clin Pract 2000;47:37-44.

33 Janand-Delenne B, Savin B, Habib G et al. Silent myocardial ischemia in patients with diabetes: who to screen. Diabetes Care 1999;22:1396-400.

34 ACSM. Guidelines for exercise testing and prescription. 6th ed. Baltimore: Lippincott, Williams, and Wilkins, 2000

35 Chipkin SR, Klugh SA, Chasan-Taber L. Exercise and diabetes. Cardiol Clin 2001;19:489-505.

36 Gordon NF. The Exercise prescription. In: Ruderman N, Devlin JT, Schneider S, et al, eds. Handbook of exercise in diabetes. 2nd ed. Alexandria, VA: American Diabetes Association, 2002:269-88

37 Fletcher GF, Balady G, Blair SN, et al. Statement on exercise: benefits and recommendations for physical activity programs for all Americans. A statement for health professionals by the Committee on Exercise and Cardiac Rehabilitation of the Council on Clinical Cardiology, American Heart Association. Circulation 1996;94 857-62

38 Blair SN, Kohl HW, Gordon NF, et al. How much physical activity is good for health? Annu Rev Public Health 1992;13:99-126.

39 Stewart KJ, Effron MB, Valenti SA, et al. Effects of diltiazem or propranolol during exercise training of hypertensives men. Med Sci Sports Exerc 1990;22:171-7.

40 Pollock ML, Franklin BA, Balady GJ, et al. AHA Science Advisory. Resistance exercise in individuals with and without cardiovascular disease: benefits, rationale, safety, and prescription: an advisory from the Committee on Exercise, Rehabilitation, and Prevention, Council on Clinical Cardiology, American Heart Association; Position paper endorsed by the American College of Sports Medicine. Circulation 2000; 101:828-33.

41 American Diabetes Association. Position statement: diabetes mellitus and exercise. Diabetes Care 2002;25(suppl 1):564-8.

42 Willey KA, Singh MA. Battling insulin resistance in elderly obese people with type 2 diabetes: bring on the heavy weights. Diabetes Care 2003:26:1580-8.

43 Feigenbaum MS, Pollock ML. Prescription of resistance training for health and disease. Med Sci Sports Exerc 1999;31:38-45.

44 Brubaker PH, Kaminsky LA, Whaley MH. Coronary artery disease: essentials of prevention and rehabilitation. Champaign, IL: Human Kinetics, 2002

45 Hornsby WG, Chetlin RD. Resistance training. In: Ruderman N, Devlin JT, Schneider S, et al, eds. Handbook of exercise in diabetes. 2nd ed. Alexandria, VA: American Diabetes Association, 2002:311-19

46 Joint National Committee on Prevention Detection, Evaluation, and Treatment of High Blood Pressure. Sixth report. Bethesda, MD: National Institutes of Health-NHLBI, National High Blood Pressure Education Program, November 1997:98-4080

47 Badenhop DT, Dunn CB, Eldridge S, et al Monitoring and management of cardiac rehabilitation patients with Type 2 diabetes. Clinical Exercise Physiology $2001 ; 3: 71-7$

48 Stewart KJ, Hiatt WR, Regensteiner JG, et al. Exercise training for claudication. N Engl J Med 2002:347:1941-51. 